\title{
Spatial and temporal variation in the natal otolith chemistry of a Hawailan reef fish: prospects for measuring population connectivity
}

\author{
Benjamin I. Ruttenberg, Scott L. Hamilton, and Robert R. Warner
}

\begin{abstract}
One of the most compelling unanswered questions in marine ecology is the extent to which local populations are connected via larval exchange. Recent work has suggested that variation in the chemistry of otoliths (earstones) of fishes may function as a natural tag, potentially allowing investigators to determine sources of individual larvae and estimate larval connectivity. We analyzed the spatial and temporal variation in natal otolith chemistry of a benthic-spawning reef fish from the Hawaiian Islands. We found no consistent chemical variation at the largest scale ( $>100 \mathrm{~km}$, among islands), but found significant variation at moderate scales (sites within islands, tens of kilometres) and small scales (clutches within sites), and chemistry of otoliths was not stable between years. These results imply that we may be able to use otolith chemistry to track larval dispersal only if the scales of dispersal match those of variation in natal otolith chemistry, and that separate natal otolith collections may be needed to track different cohorts of larvae. Finally, we found that elemental composition of recruit cores often did not match that of natal otoliths, suggesting that additional methodological development is required before we can effectively apply methods in otolith chemistry to the study of larval dispersal.

Résumé : Une des questions les plus intrigantes de l'écologie marine encore sans réponse est de savoir dans quelle mesure les populations locales sont reliées entre elles par des échanges de larves. Des travaux récents indiquent que les variations dans la chimie des otolithes des poissons peuvent servir d'étiquettes naturelles qui pourraient permettre aux chercheurs d'identifier l'origine de larves individuelles et d'estimer la connectivité larvaire. Nous analysons la variation spatiale et temporelle de la chimie des otolithes à la naissance d'un poisson de récif à reproduction benthique des îles Hawaii. Nous ne trouvons aucune variation chimique uniforme à l'échelle la plus grande (> $100 \mathrm{~km}$, entre les îles), mais il y en a une significative aux échelles moyennes (sites au sein des îles, dizaines de km) et petites (regroupements au sein des sites); la chimie des otolithes n'est pas stable d'une année à l'autre. Ces résultats ont comme conséquence qu'il sera possible d'utiliser la chimie des otolithes pour retracer la dispersion des larves, seulement si l'échelle de cette dispersion correspond à celle de la variation de la chimie des otolithes à la naissance; de plus, des collections différentes d'otolithes à la naissance seront peut-être nécessaires pour suivre différentes cohortes de larves. Enfin, nous trouvons que la composition en éléments des noyaux des recrues ne correspondent souvent pas à celle des otolithes à la naissance; cela laisse croire qu'il faudra une évolution supplémentaire de la méthodologie avant qu'on puisse efficacement utiliser les méthodes de chimie des otolithes pour étudier la dispersion des larves.
\end{abstract}

[Traduit par la Rédaction]

\section{Introduction}

How connected are marine populations? This is one of the fundamental unanswered questions in marine ecology. Many marine organisms have a relatively long benthic adult stage with low mobility and a relatively short pelagic larval phase with high dispersal potential. For species with this life history, dispersal among populations occurs almost exclusively in the larval stage, but rates of larval connectivity among local populations remain unknown for all species with a pelagic larval stage in part because larvae are small, difficult to track, and experience extremely high rates of mortality. De- spite these difficulties, measuring rates of larval exchange is necessary to further our understanding of population dynamics in many marine systems and to implement spatial management of marine resources, such as the location of marine reserves (Gaines and Roughgarden 1985; Caley et al. 1996; Shanks et al. 2003).

Over the last decade or so, investigators have employed a variety of different techniques to address questions of larval exchange and population connectivity, including genetics (Barber et al. 2002; Taylor and Hellberg 2003), mark and recapture (Jones et al. 1999, 2005), oceanographic modeling (Cowen et al. 2000, 2006; James et al. 2002), and otolith

B.I. Ruttenberg, ${ }^{1,2}$ S.L. Hamilton, and R.R. Warner. Department of Ecology, Evolution and Marine Biology and Marine Science Institute, University of California, Santa Barbara, CA 93106, USA.

${ }^{1}$ Corresponding author (e-mail: ruttenbe@lifesci.ucsb.edu).

${ }^{2}$ Present address: U.S. National Park Service, South Florida and Caribbean Inventory and Monitoring Network, 18001 Old Cutler Road, Suite 419, Palmetto Bay, FL 33157, USA. 
chemistry (Warner et al. 2005; Ruttenberg and Warner 2006), with variable success. Otolith chemistry has generated a great deal of interest and is often considered to have the most potential to measure larval exchange empirically (Campana and Thorrold 2001). Otoliths are accretions of calcium carbonate and protein in the inner ears of bony fishes used for hearing and balance. They often form growth bands that can be used to estimate the age of the fish (Victor 1986; Secor et al. 1995), and incorporate trace metals into the crystalline matrix at rates that may be related to environmental conditions (e.g., Campana 1999). Since otoliths are metabolically inert, these properties can be used to reconstruct the conditions a fish experienced at a given time (see Campana and Thorrold 2001 for a review of the properties of otoliths).

To use otolith chemistry to track larval dispersal, two pieces of information are required. First, a reference collection of material (e.g., otoliths) that represents the chemical composition of pre-pelagic, natal otoliths from potential source sites is needed. Such a collection would provide data on the chemistry of otoliths from these source sites before dispersal begins in the pelagic larval phase, thereby allowing investigators to generate an atlas of natal otolith chemistry. Second, one must be able to measure the chemistry of the cores of otoliths of newly settled recruits; the core is the part of the otolith that contains material deposited at the natal site. Ideally, data from the core of a recruit can be compared with the reference collection (i.e., the atlas) to determine the site where that recruit was produced.

While this methodology seems straightforward, obtaining the requisite data is complicated. Recent studies have shown that the relationship between environmental factors and otolith chemistry is much more complex than was once believed. Because temperature (see Elsdon and Gillanders $2003 a$ and references therein) and aquatic elemental concentration may have effects on otolith elemental concentration (e.g., Bath et al. 2000; Elsdon and Gillanders 2003b; De Vries et al. 2005), variation in environmental conditions should lead to some variation in otolith chemistry, even if those relationships are not predictable a priori (Campana 1999; Campana and Thorrold 2001). Additional evidence suggests that the chemistry of the otolith core, representing the natal portion of the otolith, is fundamentally different from that of other parts of the otolith (Brophy et al. 2004; Ruttenberg et al. 2005), and the chemical composition of natal otoliths does not appear to reflect the chemistry of water samples taken at the time of collection (Warner et al. 2005). Other recent work has found evidence for strong maternal effects on natal otolith chemical signatures (Thorrold et al. 2006). The collective implication of these findings is that it may be impossible to use proxies, such as water samples or otolith edges from resident adults, to generate the atlas of chemical signatures from sites of interest. Instead, researchers will need to have collections of natal otoliths from the potential source sites of interest.

Even with the caveat that natal otoliths themselves are likely necessary to generate a reliable atlas of chemical signatures, additional complications remain. Obtaining sufficient natal otoliths from a variety of potential source sites can be logistically challenging. Although it is easier to obtain otoliths from species that brood fertilized eggs benthi- cally or internally rather than those that spawn pelagically, it is often difficult to find brooding individuals or nests in sufficient numbers, and few studies have attempted to study natal otoliths (but see Brophy et al. 2003; Warner et al. 2005; Ruttenberg and Warner 2006). It is also unknown how these natal signatures vary over different spatial and temporal scales. Significant temporal variation in natal otolith chemistry would require a new set of collections for each cohort of dispersing larvae, whereas temporal stability may allow investigators to track multiple cohorts with a single collection of natal otoliths. However, the few studies that have examined temporal variation in the chemical composition of otoliths of fully marine species have yielded mixed results (e.g., Campana et al. 2000; Rooker et al. 2001; Gillanders 2002).

The scale of chemical variation of the natal signatures must also match the dispersal scale of the organism, and ideally collections should span a variety of scales, including those both greater than and less than the expected dispersal distance of the species. If natal chemical variation occurs over much larger or smaller scales than the dispersal potential of the species, it will provide no useful information for tracking dispersal. Many studies have found that otolith chemistry of marine species varies over large scales (Campana et al. 2000; Rooker et al. 2001; Ashford et al. 2005), but few have examined smaller scales (Chittaro et al. 2005; Brown 2006) and even fewer have examined scales of variation in natal otolith chemistry. The levels of spatial and temporal variation will strongly affect the frequency of sampling required, in both space and time. Unfortunately, levels of spatial and temporal variation are impossible to estimate a priori, and only a handful of studies have examined spatial or temporal variation in the chemical signatures of natal otoliths or statoliths, analogous structures in some mollusks (Warner et al. 2005; Zacherl 2005; Ruttenberg and Warner 2006).

In this study, we present data on chemical signatures of natal otoliths and cores of recruit otoliths from a common reef fish in the Hawaiian Islands. Our goals were threefold: (1) to examine spatial patterns in natal otolith chemistry across multiple spatial scales within years; (2) to examine annual variation at the same sites; and (3) to compare signatures from cores of recruit otoliths with those of natal otoliths. We found significant variation in natal otolith chemistry among clutches and some variation among sites, but no consistent variation among islands. Natal otolith signatures also differed among years and differed from signatures of cores of recruit otoliths. Our findings suggest that otolith chemistry may be usable for tracking larval dispersal only when the scales of dispersal match those of the variation in otolith chemical signatures and that caution is required when applying these methods to the study of larval dispersal.

\section{Materials and methods}

\section{Study system and study species}

We elected to use the main Hawaiian Islands as a study system because islands throughout the archipelago vary in rainfall, volcanism, land use patterns, and urbanization. Windward (eastern) shores of most islands tend to be wetter, 
Fig. 1. Map of the Hawaiian Islands showing collection sites. Black circles show collection sites for 2004 and gray triangles show collection sites for 2003. Only sites for which we had at least three clutches in 2003 or 2004 are shown. HLU is the arbitrary focal site on Hawaii.

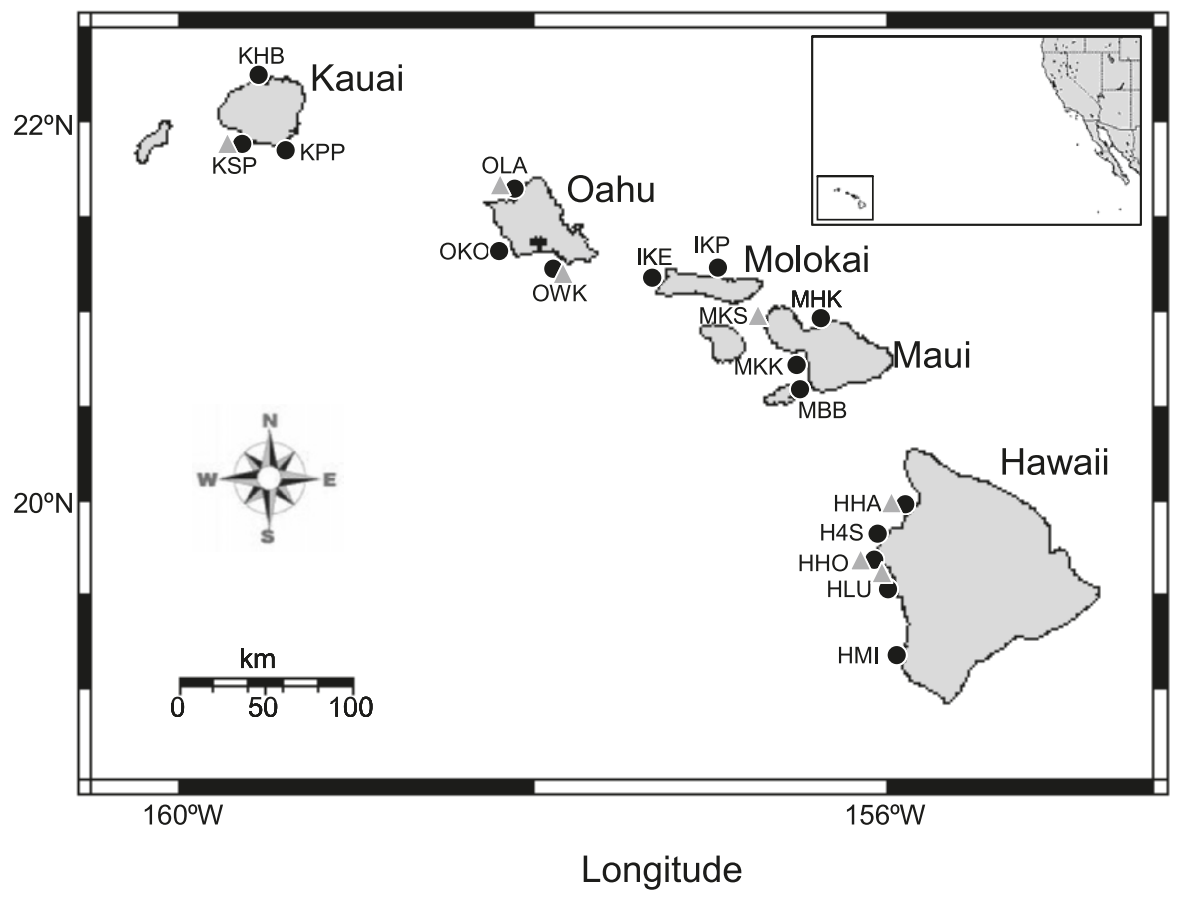

with more runoff, than leeward shores, while western islands are older and therefore have more developed and more weathered soils (Fig. 1). These differences may influence the chemistry of nearshore waters. In addition, urbanized watersheds in Hawaii have greatly elevated levels of certain trace elements (e.g., $\mathrm{Pb}$ ) compared with undeveloped areas, while nearshore waters adjacent to agricultural areas are enriched in other elements (De Carlo and Spencer 1997). Some of these chemical differences are reflected in biogenic carbonates, including fish otoliths and coral skeletons (Spencer 1997; Spencer et al. 2000).

We used the blackspot sergeant, Abudefduf sordidus, as our study species because they are common on shallow reefs throughout the islands, settle conspicuously to tide pools where they spend the first few months after settlement, and lay and guard benthic eggs on rocky surfaces in the shallow subtidal zone (usually 2-5 $\mathrm{m}$ depth). Otoliths develop a few days before hatching. These traits greatly facilitate the collection of eggs (with their natal otoliths) and recruits.

We made collections during 4- to 5-week sampling trips during summer 2003 and summer 2004. In 2003, we visited the Island of Hawaii, Maui, Kauai, and Oahu, from $13 \mathrm{Au}-$ gust to 9 September. In 2004, we visited Oahu, Kauai, Maui, Molokai, Hawaii, and Oahu, from 14 July to 19 August. On most islands, we collected eggs opportunistically from the shallow subtidal zone along semi-exposed rocky shores from sites where nesting animals were present, and we attempted to spread study sites as evenly as possible around the islands (see Fig. 1). We generally searched an area for approximately $200 \mathrm{~m}$ along the shore at each site; often no nests were found. Eggs from a given clutch were collected together and stored together. We visited many sites where no nests were present; for example, conditions were rough and access was difficult on the windward sides of most is- lands, and we found no ripe nests at any of the sites we could access on the windward side of any island. To evaluate the effects of scale on natal otolith chemistry explicitly, we sought to utilize a hierarchical sampling design along the west shore of Hawaii, where A. sordidus was most abundant. We chose a focal site arbitrarily, and attempted to sample 6 , 12,25 , and $50 \mathrm{~km}$ north and south of this point, but we were able to collect sufficient clutches from only some of these sites. From all sites on all islands, we collected a total of 44 clutches in 2003 and 124 in 2004 that yielded otoliths. Using hand nets, we collected recruits opportunistically in 2004 from tide pools from the same sites where we collected eggs. We analyzed a total of 40 recruits that were smaller than $15 \mathrm{~mm}$ standard length and likely less than a few weeks old (Table 1). However, since collections of eggs and recruits were made simultaneously at many sites, recruits were likely spawned at least a few weeks before we made collections of eggs. All samples of eggs and recruits were stored in $95 \%$ ethanol immediately after collection.

\section{Otolith preparation and analysis}

To prepare otoliths for analyses, we generally followed the methods of Warner et al. (2005), Zacherl (2005), and Ruttenberg and Warner (2006). We extracted natal otoliths by clutch by digesting the organic matter in $15 \%$ semiconductor-grade $\mathrm{H}_{2} \mathrm{O}_{2}$ buffered with $0.05 \mathrm{~N}$ Suprapure $\mathrm{NaOH}$ (hereafter, "buffered $\mathrm{H}_{2} \mathrm{O}_{2}$ ") for $30 \mathrm{~min}$ on low heat. We then transferred the otoliths to a clean beaker with $\sim 10 \mathrm{~mL}$ of fresh buffered $\mathrm{H}_{2} \mathrm{O}_{2}$ for an additional $5 \mathrm{~min}$ on low heat to remove any organic residues from the initial processing step. Next, we transferred the otoliths through four sequential rinsing steps using ultrapure water (N-pure, resistivity $>18.1 \mathrm{M} \Omega \cdot \mathrm{cm}$ ), each in a separate clean beaker. Otoliths were then pipetted onto a clean, acid-washed $20 \mathrm{~mm} \times 20 \mathrm{~mm}$ plastic slide. When the excess 
Table 1. Summary of number of collections of clutches and recruits analyzed, by island.

\begin{tabular}{|c|c|c|c|}
\hline \multirow[b]{2}{*}{ Island } & \multicolumn{2}{|c|}{ Clutches } & \multirow{2}{*}{$\frac{\text { Recruits }}{2004}$} \\
\hline & 2003 & 2004 & \\
\hline Hawaii & 19 & 49 & 12 \\
\hline Maui & 7 & 23 & 7 \\
\hline Oahu & 11 & 25 & 12 \\
\hline Kauai & 7 & 22 & 5 \\
\hline Molokai & NA & 5 & 4 \\
\hline
\end{tabular}

Note: NA, not applicable.

water evaporated, we mounted otoliths using double-sided Scotch tape. We performed all extractions in a clean lab with HEPA-filter class 100 laminar flow hoods, and all glassware was acid-washed prior to use.

We followed procedures outlined in Ruttenberg et al. (2005) and Ruttenberg and Warner (2006) to prepare recruit otoliths. From each recruit, we mounted one sagittal otolith sulcus side up on a clean, acid-washed $20 \mathrm{~mm} \times 20 \mathrm{~mm}$ slide in low-viscosity resin (Buehler Epo-Thin epoxy resin). Otoliths were polished to between $5 \mu \mathrm{m}$ and $15 \mu \mathrm{m}$ from the core using a lapping wheel with $9 \mu \mathrm{m}$ and $3 \mu \mathrm{m} 3 \mathrm{M}$ diamond polishing film. After polishing, otoliths were rinsed in $\mathrm{N}$-pure, soaked in buffered $\mathrm{H}_{2} \mathrm{O}_{2}$ in acid-leached trays for $1 \mathrm{~h}$, and soaked and rinsed an additional five times with $\mathrm{N}$ pure. Samples were then dried in class 100 laminar flow hoods and stored in covered acid-washed plastic trays until analysis.

We analyzed all samples with a Finnegan MAT Element 2-sector field inductively coupled plasma mass spectrometer (ICPMS) using a VG-UV microprobe Nd:YAG $266 \mu \mathrm{m}$ laser ablation system, with the laser pulsed at $3 \mathrm{~Hz}$ (see Ruttenberg et al. 2005 and Warner et al. 2005 for more details). We report each analyte as a ratio to $\mathrm{Ca}$, corrected for mass bias using calibration standards with known analyte to $\mathrm{Ca}$ ratios (Ruttenberg et al. 2005; Warner et al. 2005). We bracketed every four samples with calibration standards and ran blanks before each sample. Limits of detection were calculated as 3 SD of blanks for a given block. Samples were randomized across and within blocks prior to analysis.

We analyzed natal otoliths by clutch, using 12 otoliths in low resolution (resolving power $R=300$, hereafter referred to as $\mathrm{LR}$ ) for the elements ${ }^{24} \mathrm{Mg}$ (with a correction to account for ${ }^{48} \mathrm{Ca}^{2+}$ interference), ${ }^{48} \mathrm{Ca},{ }^{86} \mathrm{Sr},{ }^{138} \mathrm{Ba}$, and ${ }^{208} \mathrm{~Pb}$, and 12 otoliths in medium resolution $(R=3000$, hereafter referred to as MR) for ${ }^{48} \mathrm{Ca},{ }^{55} \mathrm{Mn},{ }^{56} \mathrm{Fe}$, and ${ }^{66} \mathrm{Zn}$. Natal otoliths were completely consumed during analysis because of their small size $(\sim 30 \mu \mathrm{m}$ in diameter, approximately equal to the laser spot size). We ablated tape blanks with each sample to ensure that the tape did not contaminate samples. For recruit otoliths, previous work has found that $\mathrm{Mn} / \mathrm{Ca}$ ratios associated with the core are elevated and that elevated $\mathrm{Mn} / \mathrm{Ca}$ ratios can be used as a proxy to identify the core (Brophy et al. 2004; Ruttenberg et al. 2005). To isolate material associated with the core only, we ablated a series of small, discrete pits using eight laser pulses in a vertical transect over the region of the otolith that was visually determined to be the core, pre-ablating the area over the core with two laser pulses to remove any surface contamination. After sample analysis, we identified the pit that contained the core using a spike in $\mathrm{Mn} / \mathrm{Ca}$ ratio as a proxy (Ruttenberg et al. 2005). Since levels of $\mathrm{Mn}$ are reliably quantifiable only in medium resolution (owing to gas interferences with ${ }^{55} \mathrm{Mn}$ in $\left.\mathrm{LR}\right)$, we collected all data for elements $(\mathrm{Mg}, \mathrm{Ca}$, $\mathrm{Mn}, \mathrm{Fe}, \mathrm{Zn}, \mathrm{Sr}, \mathrm{Ba}, \mathrm{Pb})$ for recruit cores using MR. We excluded $\mathrm{Pb}, \mathrm{Fe}$, and $\mathrm{Zn}$ from analyses of recruit cores because levels of these three elements were often below detection limits in recruit cores. We analyzed solid glass standard material from the National Institute of Standards and Technology (NIST 612) along with samples to maintain instrument precision (see Table A1 in Appendix A for these values).

\section{Data analyses}

The small amount of material associated with natal otoliths occasionally resulted in low signal stability and high percent relative standard deviation (\%RSD) of elemental ratios for a given otolith. Because the reliability of a given measurement decreases with increasing \%RSD, we applied a filter that eliminated data points with high \% RSD (Ruttenberg and Warner 2006). Because some contamination of natal otoliths is possible during sample preparation, we also filtered data points whose absolute values exceeded a prescribed maximum value for a given element, usually $\sim 2$ times greater than the maximum value observed in cores of recruits (using larger or smaller cutoff values did not change the qualitative results; see Table A2 in Appendix A for cutoff $\%$ RSD values and maximum values). This filter eliminated less than $1 \%$ of the data for $\mathrm{Mn}$ and $\mathrm{Sr}, 6 \%$ of the data for $\mathrm{Ba}$, and $9 \%$ of the data for $\mathrm{Pb}$, but eliminated over $30 \%$ of the data for $\mathrm{Mg}, \mathrm{Fe}$, and $\mathrm{Zn}$. Since these three elements $(\mathrm{Mg}, \mathrm{Fe}$, and $\mathrm{Zn})$ appeared to be much more susceptible to contamination, we excluded them from multivariate analyses and show their results for comparison only (see Results). Finally, we excluded values that fell below detection limits.

To examine broad spatial patterns in the chemistry of natal otoliths within each year, we used nested analyses of variance (ANOVAs), with island as a fixed factor and sites within islands and clutches within sites as random factors. We used nested multivariate analyses of variance (MANOVAs) with the same model design to examine these patterns for multi-elemental signatures. We included only those sites for which we had three or more clutches. We examined inter-annual patterns in natal otolith chemistry for a subset of sites for which we had at least three clutches in both years, using a model that included year, site, clutch(year, site), and the year $\times$ site interaction.

Finally, we used discriminant function analyses (DFAs) to examine spatial patterns of multivariate chemical signature variation of natal otoliths in multivariate space. Because all otoliths from a given clutch were prepared together and run together, data from individual otoliths may not be truly independent. Therefore, we use clutch means for all DFAs, such that each point in a plot represents a single clutch. We used a randomization procedure that iteratively randomizes the grouping variable with respect to the response variables to determine whether the jackknife (i.e., leave one out) reclassification success rate was significantly different from random (White and Ruttenberg 2007).

To determine whether the recruit cores resemble the natal 
otoliths from which they arose, we used the natal otolith data from 2004 as a training data set for the DFA to classify cores of recruits collected in 2004. All data were log, square root, or double square root transformed when necessary to improve normality (Appendix A, Table A2), all analyses were conducted on transformed data, and all $p$ values were corrected for multiple comparisons using the sequential Bonferroni procedure (Rice 1989). We used JMP 5.1 and SAS 8.0 (SAS Institute Inc., Cary, North Carolina), SPSS 11.0 (SPSS Inc., Chicago, Illinois), and MATLAB 5.1 (The MathWorks Inc., Natick, Massachusetts) for statistical analyses.

\section{Results}

\section{Spatial and temporal patterns in natal otoliths}

To evaluate within-year spatial patterns across multiple scales, we used univariate nested ANOVA, with island as a fixed factor and site(island) and clutch(site, island) as random factors. We found significant among-clutch variation for all elements in both years, with the exception of $\mathrm{Sr}$ in 2003. No element showed significant site-level variation in either year except $\mathrm{Ba}$ in 2004, and no element varied significantly among islands in either year (Fig. 2 and Table 2). Multivariate analyses revealed qualitatively similar patterns. A MANOVA using the same nesting as the univariate tests found significant clutch-level variation for both years, significant site-level variation in 2004 but not 2003, and no significant variation at the island level for either year (Table 3). Corroborating the results of the MANOVAs, DFAs revealed that natal otoliths had little power to classify clutches to island of origin in either year (jackknife reclassification success: $2004,29.5 \%$; 2003, 22.7\%; Fig. 3a), and neither of these reclassification success rates was significantly different from random.

When we examine patterns within islands, some spatial structure emerges. In 2004, DFA successfully reclassified $26.9 \%$ of the samples to sites on the Island of Hawaii, which span over $100 \mathrm{~km}$ (Fig. 3b). However, when using only those sites within $25 \mathrm{~km}$ of the focal site, DFA successfully reclassified $71.4 \%$ of the samples, a rate significantly different from random (Fig. 3c). Samples within Maui and Kauai were reclassified to sites at low, non-significant rates $(46.7 \%$ and $37.5 \%$ respectively; Figs. $3 d, 3 f$ ), while reclassification for sites on Oahu was significantly better than random (84.2\%; Fig. 3e). In 2003, only Hawaii and Oahu had sufficient sample sizes to analyze within-island patterns. Reclassification success rates were $20 \%$ for Hawaii and $85.7 \%$ for Oahu, neither of which was significantly different from random (likely a consequence of small sample size for Oahu).

To determine the temporal stability of natal otolith chemical signatures, we compared natal otoliths from sites for which we had at least three clutches in both 2003 and 2004. Univariate analyses found no significant differences between years, among sites, or for their interaction for any of the four elements for which we had reliable data $(\mathrm{Mn}, \mathrm{Sr}, \mathrm{Ba}$, $\mathrm{Pb}$; Fig. 4). A MANOVA also found no differences between years (Table 3) but found significant variation among sites and among clutches, and a significant site by year interaction. However, when we used the 2004 data from Hawaii and Oahu as training data sets to classify the 2003 samples
Fig. 2. Means of natal otolith chemistry, by element, island, and year. Black bars indicate 2003 data; gray bars are for 2004. Error bars are \pm 1 standard error (SE).
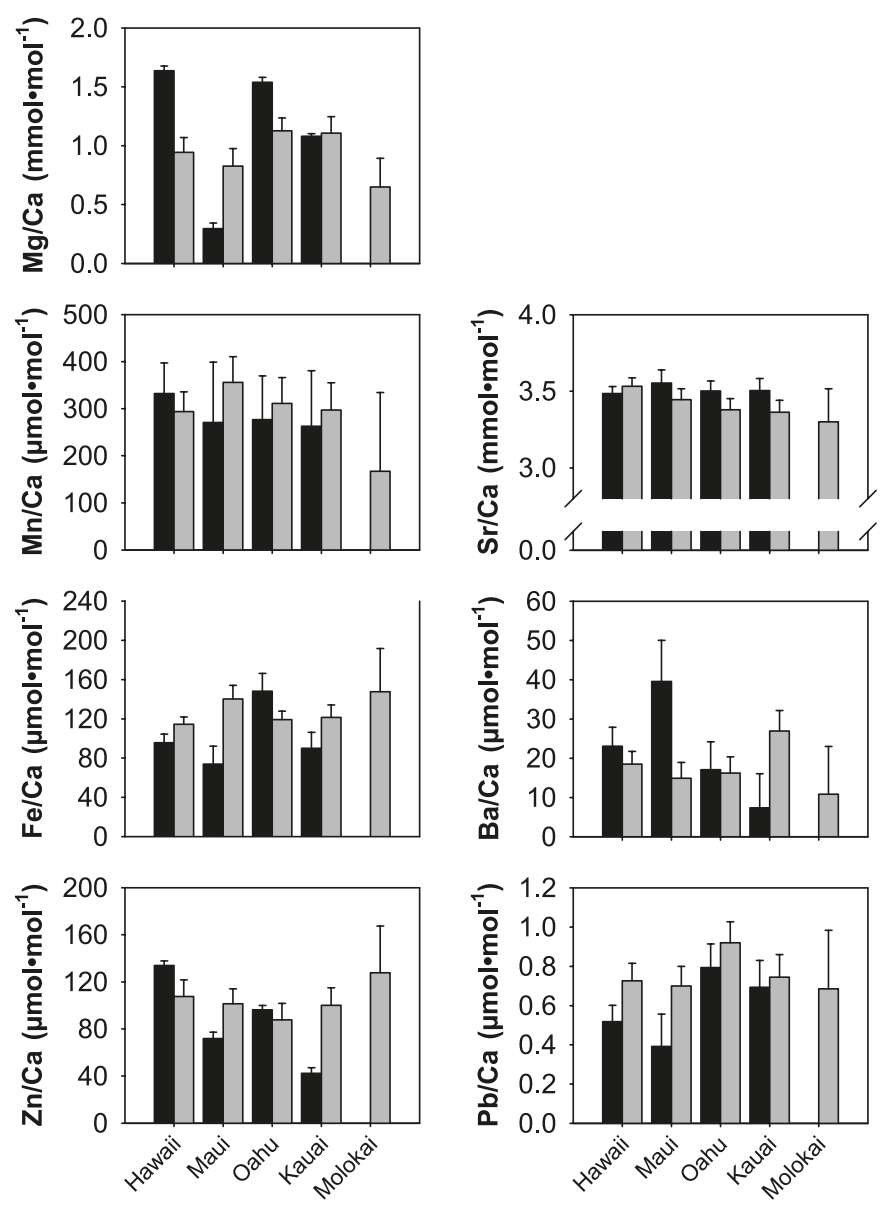

Island

from those islands, the DFAs performed poorly (33\% and $14 \%$ of 2003 samples correctly reclassified to site using 2004 data on Hawaii and Oahu, respectively).

\section{Cores of recruit otoliths}

To use otolith chemistry to track larval dispersal, chemistry of recruit cores should match that of natal otoliths, assuming that recruits are not originating from an unsampled area with distinctive otolith chemistry. Because values for $\mathrm{Pb}, \mathrm{Fe}$, and $\mathrm{Zn}$ were consistently below detection limits for recruit cores (see Materials and methods), we were able to compare natal otoliths and recruit cores only for $\mathrm{Mg}, \mathrm{Mn}$, $\mathrm{Sr}$, and $\mathrm{Ba}$. For $\mathrm{Mg}, \mathrm{Sr}$, and $\mathrm{Ba}$, concentrations in natal otoliths were significantly greater than those in recruit cores $(p<0.001$; Fig. 5). However, levels of Mn were marginally higher in recruit cores than in natal otoliths $(p=0.06$; Fig. 5).

Although there appears to be little usable variation in natal otolith signatures among islands, there is usable variation within some islands. Therefore, it is still worthwhile to see how well the recruit cores match the natal otolith signatures in multivariate space for the entire archipelago (classifying to island), and within select sites on Hawaii and Oahu (classifying to site). Some of the recruits fall into the DFA space 
Table 2. Univariate analysis of variance (ANOVA) results for natal otoliths.

\begin{tabular}{|c|c|c|c|c|c|c|c|c|c|}
\hline \multirow[b]{2}{*}{ Element } & \multirow[b]{2}{*}{ Source } & \multicolumn{4}{|c|}{2003} & \multicolumn{4}{|c|}{2004} \\
\hline & & $\mathrm{df}$ & MS & $F$ & $\% \mathrm{VC}$ & $\mathrm{df}$ & MS & $F$ & $\% \mathrm{VC}$ \\
\hline \multirow[t]{4}{*}{$\mathrm{Mg}$} & Island & 2 & 1.46 & 22.42 & & 3 & 5.29 & 2.66 & \\
\hline & Site(Island) & 4 & 0.09 & 0.61 & 0 & 10 & 2.86 & 1.31 & 4.6 \\
\hline & Clutch(Site, Island) & 5 & 0.27 & 3.16 & 16.7 & 51 & 2.68 & $19.70 * * *$ & 62.4 \\
\hline & Error & 100 & 0.09 & & 83.3 & 604 & 0.14 & & 33.0 \\
\hline \multirow[t]{4}{*}{ Mn } & Island & 2 & 0.81 & 0.13 & & 3 & 0.79 & 0.13 & \\
\hline & Site(Island) & 4 & 5.36 & 1.05 & 0.8 & 10 & 6.20 & 0.82 & 0 \\
\hline & Clutch(Site, Island) & 9 & 5.45 & $6.86 * * *$ & 30.4 & 52 & 8.08 & $7.27 * * *$ & 33.1 \\
\hline & Error & 204 & 0.79 & & 68.8 & 745 & 1.11 & & 66.9 \\
\hline \multirow[t]{4}{*}{$\mathrm{Fe}$} & Island & 2 & 29.13 & 1.27 & & 3 & 20.57 & 0.34 & \\
\hline & Site(Island) & 4 & 19.76 & 0.33 & 2.8 & 10 & 66.01 & 1.48 & 6.0 \\
\hline & Clutch(Site, Island) & 9 & 60.28 & $11.88 * * *$ & 29.1 & 50 & 54.76 & $10.75 * * *$ & 48.7 \\
\hline & Error & 121 & 5.07 & & 68.0 & 542 & 5.09 & & 45.3 \\
\hline \multirow[t]{4}{*}{$\mathrm{Zn}$} & Island & 2 & 247.56 & . & & 3 & 38.01 & 0.79 & \\
\hline & Site(Island) & 4 & 3.32 & 0.14 & 0 & 10 & 53.27 & 1.14 & 2.0 \\
\hline & Clutch(Site, Island) & 7 & 26.03 & $3.61 * *$ & 54.9 & 49 & 63.25 & $11.50 * * *$ & 54.2 \\
\hline & Error & 122 & 7.22 & & 45.1 & 494 & 5.50 & & 43.8 \\
\hline \multirow[t]{4}{*}{$\mathrm{Sr}$} & Island & 2 & 0.01 & 0.07 & & 3 & 1.04 & 0.94 & \\
\hline & Site(Island) & 4 & 0.16 & 0.57 & 0 & 10 & 1.13 & 1.57 & 3.2 \\
\hline & Clutch(Site, Island) & 9 & 0.29 & 1.97 & 5.0 & 52 & 0.75 & $4.42 * * *$ & 20.0 \\
\hline & Error & 234 & 0.15 & & 95.0 & 813 & 0.17 & & 76.8 \\
\hline \multirow[t]{4}{*}{$\mathrm{Ba}$} & Island & 2 & 12.55 & 1.68 & & 3 & 2.44 & 0.26 & \\
\hline & Site(Island) & 4 & 6.12 & 1.53 & 14.8 & 10 & 9.62 & $3.29 *$ & 24.6 \\
\hline & Clutch(Site, Island) & 9 & 4.29 & $36.36 * * *$ & 60.5 & 52 & 3.07 & $22.92 * * *$ & 47.3 \\
\hline & Error & 228 & 0.12 & & 24.8 & 803 & 0.13 & 0.26 & 28.0 \\
\hline \multirow[t]{4}{*}{$\mathrm{Pb}$} & Island & 2 & 5.50 & 2.48 & & 3 & 3.34 & 0.61 & \\
\hline & Site(Island) & 4 & 1.73 & 0.73 & 0 & 10 & 5.68 & 2.59 & 15.0 \\
\hline & Clutch(Site, Island) & 9 & 2.68 & $6.67 * * *$ & 32.5 & 52 & 2.41 & $10.33 * * *$ & 39.4 \\
\hline & Error & 203 & 0.40 & & 67.5 & 662 & 0.23 & & 45.6 \\
\hline
\end{tabular}

Note: For all analyses, Island was a fixed factor, and Site(Island) and Clutch(Site, Island) were random factors. \%VC is the variance component percentage. Bonferroni-corrected $p$ values: ${ }^{*}, p<0.05 ; * *, p<0.01$; ***, $p<0.0001$.

Table 3. Results from nested multivariate analyses of variance (MANOVAs).

\begin{tabular}{llllc}
\hline Data used & Level & Pillai's trace & df (numerator, denominator) & $F$ \\
\hline 2003 & Island & 1.81 & 9,12 & 2.03 \\
& Site(Island) & 0.58 & 12,42 & 0.83 \\
\multirow{4}{*}{2004} & Clutch(Site, Island) & 0.92 & 42,753 & $7.96^{* * *}$ \\
& Island & 0.37 & 9,30 & 0.47 \\
& Site(Island) & 0.84 & 30,186 & $2.41^{* *}$ \\
\multirow{4}{*}{ Year } & Clutch(Site, Island) & 1.39 & 186,2286 & $10.64^{* * *}$ \\
& Year & 0.10 & 3,37 & 1.38 \\
& Site & 0.67 & 18,117 & $1.67 *$ \\
& Clutch(Year, Site) & 1.22 & 117,1785 & $10.40^{* * *}$ \\
& Year $\times$ Site & 0.56 & 18,1785 & $22.96^{* * *}$ \\
\hline
\end{tabular}

Note: For 2003 and 2004 tests, Island was a fixed factor, and Site(Island) and Clutch(Site, Island) were random factors. For the test of year, Year, Site, and their interaction were fixed factors, and Clutch(Year, Site) was a random factor. All tests used LR elements (Sr, Ba, Pb). $p$ values: *, $p=0.05$; **, $p<0.01$; ***, $p<$ 0.0001 .

created by the natal otoliths, but many do not $(53 \%, 42 \%$, and $36 \%$ of recruit cores fell outside of the $95 \%$ confidence space of the natal otoliths for all islands, Hawaii, and Oahu, respectively; Fig. 6).

\section{Discussion}

To use otolith chemistry to track larval dispersal, re- searchers must be able to characterize the chemistry of the natal portion of recruit otoliths (i.e., the core) and match that signature with an atlas of natal otolith signatures from potential source areas. Because the natal portion of otoliths appears to be enriched relative to non-natal otolith material (Brophy et al. 2004; Ruttenberg et al. 2005) and natal otolith chemistry may not match that of the surrounding water (Warner et al. 2005), it will be necessary to use natal oto- 
Fig. 3. Discriminant function analysis (DFA) of clutch means for 2004. Jackknife reclassification success in parentheses follows the description of each panel. (a) All islands (27.6\%); (b) Hawaii, all sites (26.9\%); (c) Hawaii, sites within $25 \mathrm{~km}$ of the focal site (71.6\%); (d) Maui (46.7\%); (e) Oahu (84.2\%); (f) Kauai (37.5\%).

See Table A3 in Appendix A for DFA loadings.
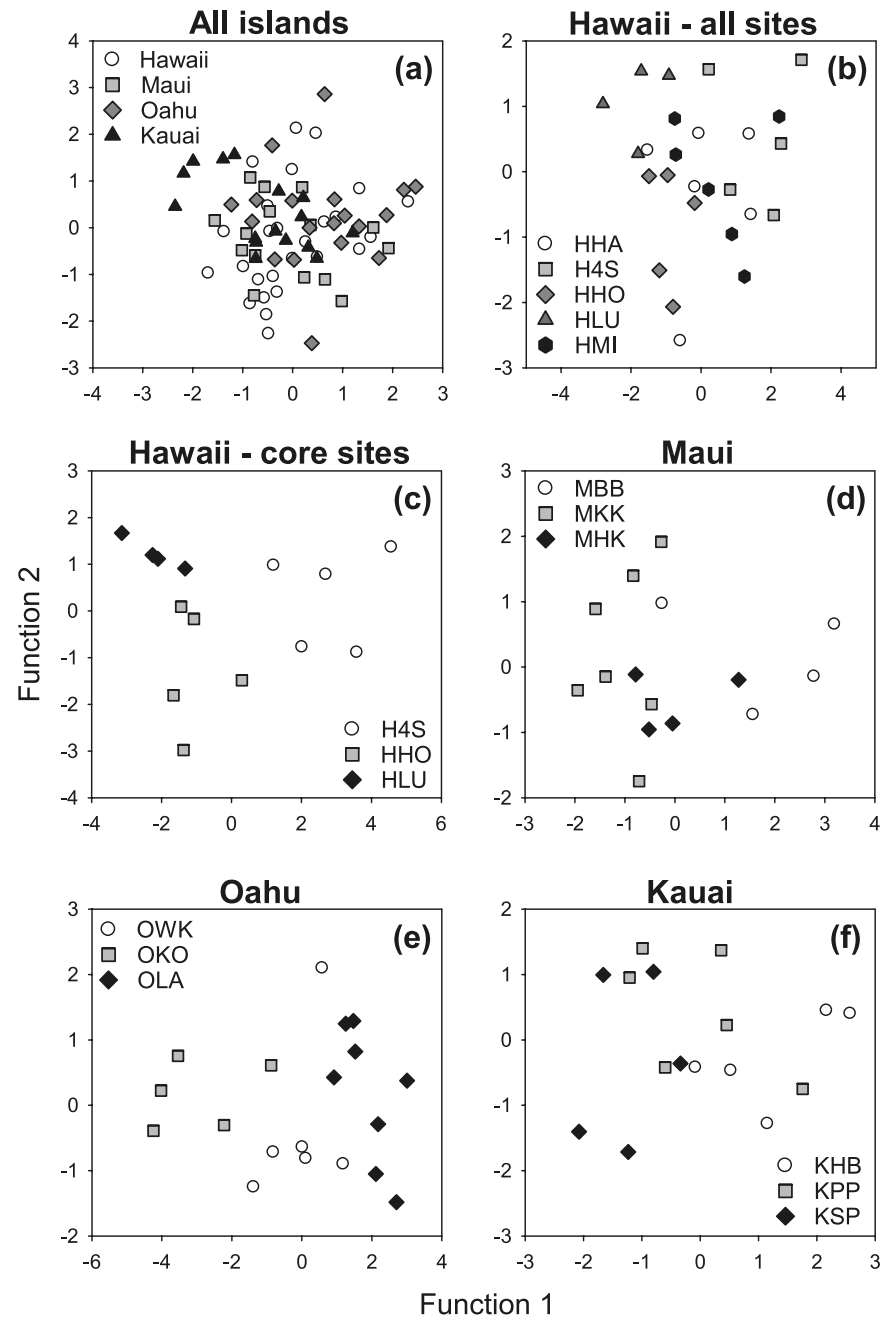

liths collected from potential source areas to generate the atlas of natal otolith chemistry.

The first step in any study of this kind is to determine the scales over which the chemistry of natal otoliths varies. A few recent studies have found some variation over moderate scales (few tens of kilometres), but no consistent patterns over larger scales (>150 km, Warner et al. 2005; Ruttenberg and Warner 2006). In this study, we expected the strong gradients in population, land use, rainfall/runoff, and volcanism among the main Hawaiian Islands to create gradients in aquatic chemistry (De Carlo and Spencer 1997; De Carlo and Anthony 2002) and, consequently, the chemistry of natal otoliths (Spencer et al. 2000). We found no patterns among islands using either univariate or multivariate tests. However, there was some variation at smaller scales: two of the four islands we examined showed multivariate patterns among sites within each island. Interestingly, this pattern was apparent on the Island of Hawaii only when we included sites that were within $25 \mathrm{~km}$ of the arbitrarily defined
Fig. 4. Annual mean elemental concentrations recorded in natal otoliths, including only those sites for which there were at least three clutches in 2004 and 2003. Error bars are \pm 1 standard error (SE).
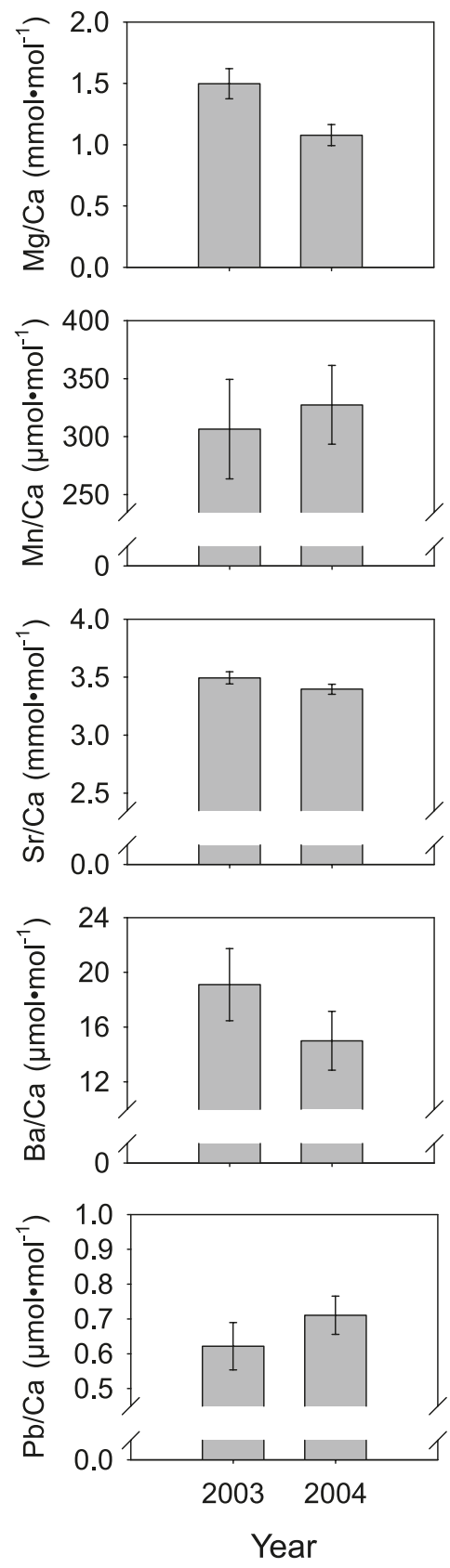

focal site; when we included all sites, which spanned around $100 \mathrm{~km}$, jackknife reclassification success rates dropped from $72 \%$ to $27 \%$ (with a corresponding change in $p$ values from 0.01 to 0.3 ).

Natal otolith chemistry may be inherently variable over small scales, possibly because of small-scale changes in oceanography, anthropogenic inputs, or other unknown factors. Small-scale sampling would detect this small-scale variation, while nested sampling at larger scales would replicate the small-scale pattern within each larger sampling unit and obscure patterns at larger scales. There was some sign of this effect in the hierarchical sampling scheme along the west 
Fig. 5. Mean elemental concentrations for natal otoliths and recruit cores for 2004. Error bars are \pm 1 standard error (SE).
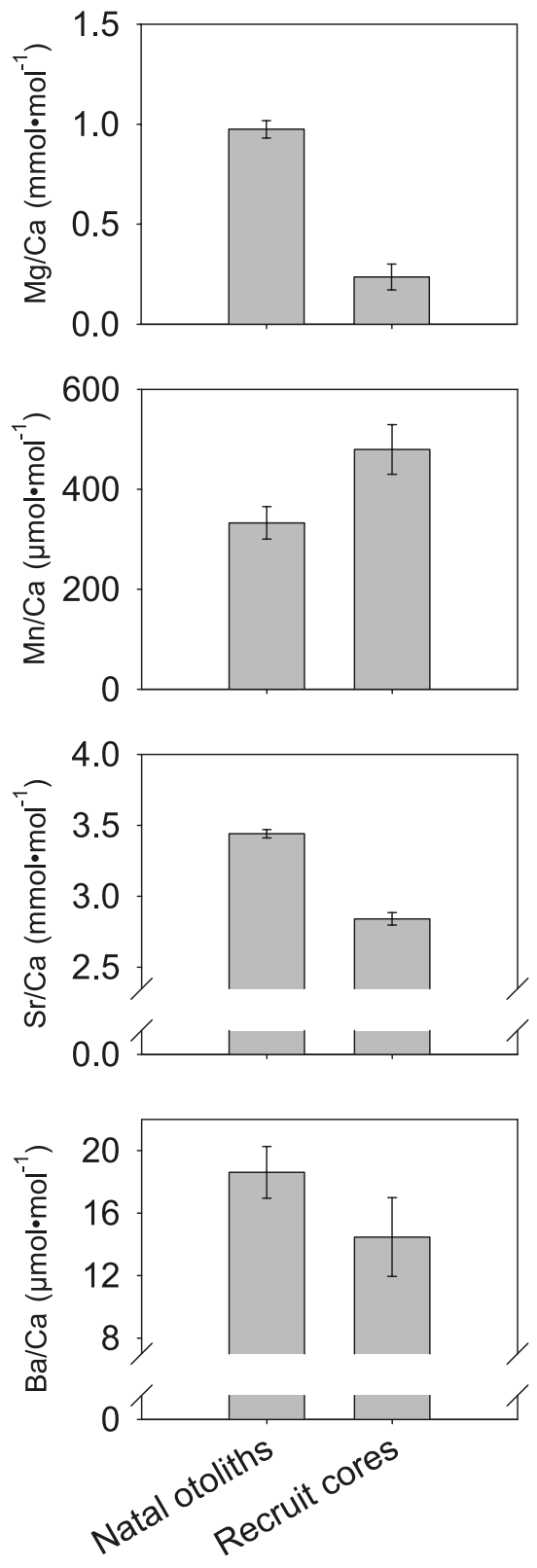

\section{Otolith type}

shore of Hawaii, but small sample sizes limited our ability to fully test this idea. If sites are inherently variable over small scales, selecting a few sites from each region or island (as in this study and in Warner et al. 2005 and Ruttenberg and Warner 2006) would likely generate some structure over small scales but none over larger ones. While it is still unknown what factors might drive small-scale variation in natal otolith chemistry, the fact that the same patterns appear in three separate studies suggests that variation at this scale may be common. Additional studies using different species in other systems are needed to confirm these preliminary findings. The presence of small-scale variation in natal otolith chemistry will greatly complicate our ability to use these techniques to track larval dispersal. Even if no
Fig. 6. Discriminant function analyses (DFAs) of natal otoliths and classifications of recruit cores for 2004. Discriminant functions and 95\% confidence ellipses were generated using clutch means for Mn, $\mathrm{Sr}$, and $\mathrm{Ba}$, and recruit cores were classified using these functions, with jackknife values for each DFA in parentheses. (a) All islands and all recruits (22.8\%); (b) Hawaii, using sites within $25 \mathrm{~km}$ of the focal site only and recruits from those sites $(71.4 \%)$; (c) Oahu, with recruits collected on Oahu (80.0\%). See Table A3 in Appendix A for DFA loadings.
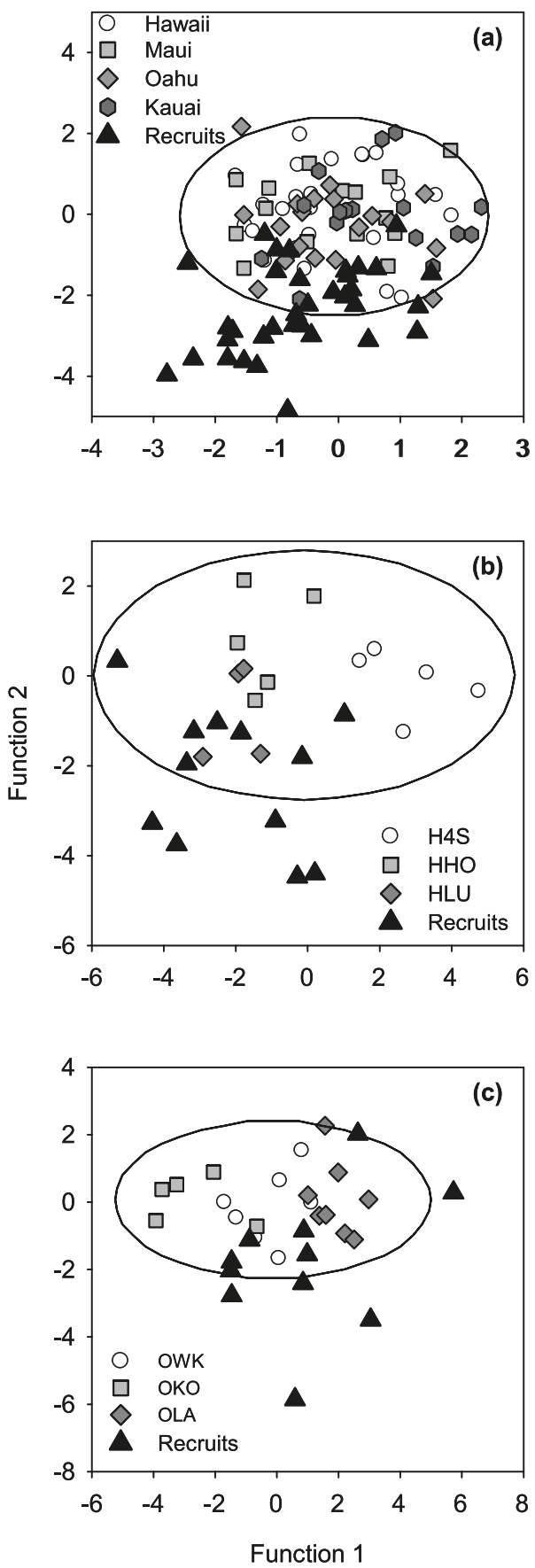

structure exists over larger scales, some spatial structure is likely to emerge when studies include only a few sites at smaller scales. However, this apparent small-scale structure may not accurately characterize the true spatial structure, even over small scales. 
In addition to some variation among sites within islands, we also found significant variation among clutches for all analyses that included clutch as a nested term. Other studies that have examined the chemistry of natal otoliths and statoliths have all found significant variation at the clutch or brood level (Warner et al. 2005; Zacherl 2005; Ruttenberg and Warner 2006), and other recent work has found strong maternal effects on the composition of the natal portion of the otolith (Thorrold et al. 2006). These findings suggest that variation in maternal factors may have a strong influence on the chemical composition of the natal portion of fish otoliths (and possibly mollusk statoliths); these maternal effects may further confound any spatial patterns in water chemistry and otolith chemistry.

It is also possible that some of the clutch-level effects were the result of some contamination during sample processing, since natal otoliths were processed and run in batches by clutch. However, it seems unlikely that all of the clutch-level variation is attributable to processing artifacts. We used previously published protocols (Warner et al. 2005; Zacherl 2005) and modified them to include an additional cleaning step to further minimize any contamination during processing. Preliminary experiments demonstrated that levels of a number of elements were significantly reduced by adding the second peroxide cleaning step (B. Ruttenberg and S. Hamilton, unpublished data). In addition, while some elements may be more susceptible to contamination (e.g., $\mathrm{Fe}, \mathrm{Pb}$ ), others should be impervious to contamination (e.g., Sr), and we found clutch-level effects for nearly all elements in both years. Finally, any contamination would have obscured any true variation, and we still observed significant within-island variation for two islands using clutch means. While these data suggest that contamination during sample processing was minor, we cannot rule out the possibility that contamination influenced variation at the clutch level.

In addition to understanding how natal otolith chemistry varies in space, it is also important to understand how natal chemical signatures vary in time. Previous work has generated conflicting results using non-natal otolith material (see Gillanders 2002, 2005 for reviews); some studies reported relative temporal stability in otolith chemistry (Thorrold et al. 1998; Campana et al. 2000), others found significant temporal variability (Rooker et al. 2001; Gillanders 2002; Swearer et al. 2003), and a few found a mix of stability and variability, depending on the scale or the elements used (Gillanders and Kingsford 2000; Brown 2006). While we found no univariate or multivariate differences in chemical signatures among years, DFAs were unable to classify 2003 samples accurately to site using the 2004 data as a training data set for either Hawaii or Oahu (the two islands for which we had samples from multiple sites in both years, using only sites that had sufficient samples in both years). If a training data set from one year cannot reliably classify samples from another year, investigators may need to collect natal otoliths for each recruit cohort they sample.

A number of previous studies have found spatial differences in otolith chemistry and suggested that this variation may be used to track larval dispersal (e.g., Ashford et al. 2005; Chittaro et al. 2005). Fewer studies have examined spatial variation in the natal portion of the otolith or statolith
(Warner et al. 2005; Zacherl 2005; Ruttenberg and Warner 2006). However, using otolith chemistry to track larval dispersal also requires information about the chemistry of otolith cores of newly settled recruits. Values from recruit cores should overlap with values from natal otoliths, since the natal portion of the otolith ultimately comprises the core of the otolith as the fish grows. A few other studies have examined both natal otoliths and recruit cores; Ruttenberg and Warner (2006) found that levels of all elements were higher in natal otoliths than in recruit cores. They attributed these differences to the inclusion of non-core material during the ablation of the enriched otolith cores (i.e., dilution of the core by non-core, non-enriched material). Standish et al. (2008) found that some elements were higher in natal otoliths but others were higher in recruit cores.

In this study, we found that most elements $(\mathrm{Mg}, \mathrm{Sr}$, and $\mathrm{Ba}$ ) were significantly higher in natal otoliths than in recruit cores. Differences in Mn were only marginally significant $(p=0.06)$ but trended in the opposite direction. With differences in nearly all elements, many of the recruits fell outside of the $95 \%$ confidence space created by natal otoliths $(53 \%, 42 \%$, and $36 \%$ for all islands, Hawaii, and Oahu, respectively). Even though data on $\mathrm{Mg}, \mathrm{Sr}$, and $\mathrm{Ba}$ were collected in MR from otolith cores and in LR from natal otoliths, there were no differences between MR and LR in measured concentrations of NIST standards for any element. Since we used methodologies similar to those of Ruttenberg and Warner (2006), it seems likely that the inclusion of noncore material is also responsible for the differences that we observed in most elements. However, this explanation cannot account for differences in $\mathrm{Mn}$ that trended in the opposite direction, and we are uncertain why $\mathrm{Mn}$ seems to behave differently than other elements in this study. Differences between natal otoliths and recruit cores could occur if the majority of recruits we collected were from unsampled and chemically distinct locations, but given that we sampled from multiple sites on the five largest islands in the Hawaiian chain, which span $500 \mathrm{~km}$, this seems unlikely, especially given that we found no clear patterns over large scales in the chemistry of natal otoliths. Regardless of the cause, additional work is needed to determine how to appropriately sample the cores of recruit otoliths. We suggest that using a laser with a smaller spot size (such as a $213 \mathrm{~nm}$ or $193 \mathrm{~nm}$ laser) or using fewer pulses in each pit may help sample the area around the core more precisely, reducing the potential inclusion of non-core material.

In this study, we provide evidence that the chemical composition of natal otoliths of a reef fish may vary over small to moderate spatial scales (tens of kilometres) but not larger ones $(<100 \mathrm{~km})$ in the Hawaiian Islands. In addition, we found that natal signatures may not be temporally stable and that our measurements of cores of recruits may not adequately sample the natal portion of the otolith. The ideal study system to examine larval connectivity along open coasts would find temporally stable variation in natal otolith chemistry over scales that match the potential dispersal distance of the species in question (likely many tens of kilometres to $100 \mathrm{~km}$ in fishes), with little variation over smaller scales (Becker et al. 2005). Estuarine systems often have these characteristics, and otolith chemistry has been applied successfully to track movement of juveniles and 
adults (Thorrold et al. 2001; Gillanders 2005), but many of the systems that have been used to track larval dispersal do not have these characteristics. Unfortunately, our results generally match those of the few previous studies of natal otolith chemistry that found significant variation only over smaller scales. Other methods, such as transgenerational marking (e.g., Thorrold et al. 2006), may be more likely to provide reliable data on larval sources. Even though the use of natural variation in otolith chemistry does have the potential to measure larval connectivity, studies must be designed to examine patterns of variation over multiple scales and additional methodological development is needed before investigators will be able to apply these techniques successfully.

\section{Acknowledgements}

Funding for this study was provided by the US National Park Service Pacific Islands Coral Reef Program and by PISCO, the Partnership for Interdisciplinary Studies of Coastal Oceans, funded primarily by the Gordon and Betty Moore Foundation and David and Lucile Packard Foundation. We are deeply indebted to M. Roux, J.S. White, and B. Brady for their patience, tolerance, positive attitudes, and outstanding service in the field. We thank G. Paradis and M. Sheehy for assistance with the ICPMS, and B. Allen, M. Donovan, C. Grigsby, L.L. Hamady, M. Kissinger, K. Ohlinger, N. Roper, and N. Sofer for assistance with processing and preparing samples. Two anonymous reviewers provided excellent feedback that greatly improved the manuscript. This is PISCO contribution No. 277.

\section{References}

Ashford, J.R., Jones, C.M., Hofmann, E., Everson, I., Moreno, C., Duhamel, G., and Williams, R. 2005. Can otolith elemental signatures record the capture site of Patagonian toothfish (Dissostichus eleginoides), a fully marine fish in the Southern Ocean? Can. J. Fish. Aquat. Sci. 62: 2832-2840. doi:10.1139/f05-191.

Barber, P.H., Palumbi, S.R., Erdmann, M.V., and Moosa, M.K. 2002. Sharp genetic breaks among populations of Haptosquilla pulchella (Stomatopoda) indicate limits to larval transport: patterns, causes, and consequences. Mol. Ecol. 11: 659-674. doi:10.1046/j.1365-294X.2002.01468.x. PMID:11972755.

Bath, G.E., Thorrold, S.R., Jones, C.M., Campana, S.E., McLaren, J.W., and Lam, J.W.H. 2000. Strontium and barium uptake in aragonitic otoliths of marine fish. Geochim. Cosmochim. Acta, 64: 1705-1714. doi:10.1016/S0016-7037(99)00419-6.

Becker, B.J., Fodrie, F.J., McMillan, P.A., and Levin, L.A. 2005. Spatial and temporal variation in trace elemental fingerprints of mytilid mussel shells: a precursor to invertebrate larval tracking. Limnol. Oceanogr. 50: 48-61.

Brophy, D., Danilowicz, B.S., and Jeffries, T.E. 2003. The detection of elements in larval otoliths from Atlantic herring using laser ablation ICP-MS. J. Fish Biol. 63: 990-1007. doi:10.1046/j. 1095-8649.2003.00223.x.

Brophy, D., Jeffries, T.E., and Danilowicz, B.S. 2004. Elevated manganese concentrations at the cores of clupeid otoliths: possible environmental, physiological, or structural origins. Mar. Biol. (Berl.), 144: 779-786. doi:10.1007/s00227-003-1240-3.

Brown, J.A. 2006. Classification of juvenile flatfishes to estuarine and coastal habitats based on the elemental composition of otoliths. Estuar. Coast. Shelf Sci. 66: 594-611. doi:10.1016/j.ecss. 2005.11.005.

Caley, M.J., Carr, M.H., Hixon, M.A., Hughes, T.P., Jones, G.P., and Menge, B.A. 1996. Recruitment and the local dynamics of open marine populations. Annu. Rev. Ecol. Syst. 27: 477-500. doi:10.1146/annurev.ecolsys.27.1.477.

Campana, S.E. 1999. Chemistry and composition of fish otoliths: pathways, mechanisms and applications. Mar. Ecol. Prog. Ser. 188: 263-297. doi:10.3354/meps188263.

Campana, S.E., and Thorrold, S.R. 2001. Otoliths, increments, and elements: keys to a comprehensive understanding of fish populations? Can. J. Fish. Aquat. Sci. 58: 30-38. doi:10.1139/cjfas-58$1-30$.

Campana, S.E., Chouinard, G.A., Hanson, J.M., Frechet, A., and Brattey, J. 2000. Otolith elemental fingerprints as biological tracers of fish stocks. Fish. Res. 46: 343-357. doi:10.1016/S01657836(00)00158-2.

Chittaro, P.M., Usseglio, P., Fryer, B.J., and Sale, P.F. 2005. Using otolith microchemistry of Haemulon flavolineatum (French Grunt) to characterize mangroves and coral reefs throughout Turneffe Atoll, Belize: difficulties at small spatial scales. Estuaries, 28: 373-381.

Cowen, R.K., Lwiza, K.M., Sponaugle, S., Paris, C.B., and Olson, D.B. 2000. Connectivity of marine populations: open or closed? Science (Washington, D.C.), 287: 857-859. doi:10.1126/science. 287.5454.857. PMID:10657300.

Cowen, R.K., Paris, C.B., and Srinivasan, A. 2006. Scaling of connectivity in marine populations. Science (Washington, D.C.), 311: 522-527. doi:10.1126/science.1122039. PMID:16357224.

De Carlo, E.H., and Anthony, S.S. 2002. Spatial and temporal variability of trace element concentrations in an urban subtropical watershed, Honolulu, Hawaii. Appl. Geochem. 17: 475-492. doi:10.1016/S0883-2927(01)00114-7.

De Carlo, E.H., and Spencer, K.J.H. 1997. Retrospective analysis of anthropogenic inputs of lead and other heavy metals to the Hawaiian sedimentary environment. Appl. Organomet. Chem. 11: 415-437. doi:10.1002/(SICI)1099-0739(199705)11:5<415::AIDAOC599>3.0.CO;2-P.

De Vries, M.C., Gillanders, B.M., and Elsdon, T.S. 2005. Facilitation of barium uptake into fish otoliths: influence of strontium concentration and salinity. Geochim. Cosmochim. Acta, 69: 4061-4072. doi:10.1016/j.gca.2005.03.052.

Elsdon, T.S., and Gillanders, B.M. 2003a. Reconstructing migratory patterns of fish based on environmental influences on otolith chemistry. Rev. Fish Biol. Fish. 13: 219-235.

Elsdon, T.S., and Gillanders, B.M. 2003b. Relationship between water and otolith elemental concentrations in juvenile black bream Acanthopagrus butcheri. Mar. Ecol. Prog. Ser. 260: 263 272. doi: $10.3354 /$ meps 260263.

Gaines, S.D., and Roughgarden, J. 1985. Larval settlement rate: a leading determinant of structure in an ecological community of the marine intertidal zone. Proc. Natl. Acad. Sci. U.S.A. 82: 3707-3711. doi:10.1073/pnas.82.11.3707. PMID:16593571.

Gillanders, B.M. 2002. Temporal and spatial variability in elemental composition of otoliths: implications for determining stock identity and connectivity of populations. Can. J. Fish. Aquat. Sci. 59: 669-679. doi:10.1139/f02-040.

Gillanders, B.M. 2005. Using elemental chemistry of fish otoliths to determine connectivity between estuarine and coastal habitats. Estuar. Coast. Shelf Sci. 64: 47-57. doi:10.1016/j.ecss.2005.02.005.

Gillanders, B.M., and Kingsford, M.J. 2000. Elemental fingerprints of otoliths of fish may distinguish estuarine 'nursery' habitats. Mar. Ecol. Prog. Ser. 201: 273-286. doi:10.3354/meps201273.

James, M.K., Armsworth, P.R., Mason, L.B., and Bode, L. 2002. The structure of reef fish metapopulations: modelling larval dispersal and retention patterns. Proc. R. Soc. Lond. B Biol. Sci. 269: 2079-2086. doi:10.1098/rspb.2002.2128. 
Jones, G.P., Milicich, M.J., Emslie, M.J., and Lunow, C. 1999. Self-recruitment in a coral reef fish population. Nature (London), 402: 802-804. doi:10.1038/45538.

Jones, G.P., Planes, S., and Thorrold, S.R. 2005. Coral reef fish larvae settle close to home. Curr. Biol. 15: 1314-1318. doi:10. 1016/j.cub.2005.06.061. PMID:16051176.

Rice, W.R. 1989. Analyzing tables of statistical tests. Evolution, 43: 223-225. doi:10.2307/2409177.

Rooker, J.R., Secor, D.H., Zdanowicz, V.S., and Itoh, T. 2001. Discrimination of northern bluefin tuna from nursery areas in the Pacific Ocean using otolith chemistry. Mar. Ecol. Prog. Ser. 218: 275-282. doi:10.3354/meps 218275.

Ruttenberg, B.I., and Warner, R.R. 2006. Spatial variation in the chemical composition of natal otoliths from a reef fish in the Galápagos Islands. Mar. Ecol. Prog. Ser. 328: 225-236. doi:10. 3354/meps328225.

Ruttenberg, B.I., Hamilton, S.L., Hickford, M.J.H., Paradis, G.L., Sheehy, M.S., Standish, J.D., Ben-Tzvi, O., and Warner, R.R. 2005. Elevated levels of trace elements in cores of otoliths and their potential for use as natural tags. Mar. Ecol. Prog. Ser. 297: 273-281. doi:10.3354/meps297273.

Secor, D.H., Dean, J.M., and Campana, S.E. 1995. Recent developments in fish otolith research. University of South Carolina Press, Columbia, S.C.

Shanks, A.L., Grantham, B.A., and Carr, M.H. 2003. Propagule dispersal distance and the size and spacing of marine reserves. Ecol. Appl. 13(Suppl.): 159-169.

Spencer, K.J. 1997. Sources and fluxes of anthropogenic $\mathrm{Pb}$ in the coastal ocean, Oahu, Hawaii as measured in coral species $P$. lobata. Eos, 78: F211.

Spencer, K., Shafer, D.J., Gauldie, R.W., and DeCarlo, E.H. 2000. Stable lead isotope ratios from distinct anthropogenic sources in fish otoliths: a potential nursery ground stock marker. Comp. Biochem. Physiol. A, 127: 273-284. doi:10.1016/S10956433(00)00260-9.

Standish, J.D., Sheehy, M.S., and Warner, R.R. 2008. Use of otolith natal elemental signatures as natural tags to evaluate con- nectivity among open-coast fish populations. Mar. Ecol. Prog. Ser. In press.

Swearer, S.E., Forrester, G.E., Steele, M.A., Brooks, A.J., and Lea, D.W. 2003. Spatio-temporal and interspecific variation in otolith trace-elemental fingerprints in a temperate estuarine fish assemblage. Estuar. Coast. Shelf Sci. 56: 1111-1123. doi:10.1016/ S0272-7714(02)00317-7.

Taylor, M.S., and Hellberg, M.E. 2003. Genetic evidence for local retention of pelagic larvae in a Caribbean reef fish. Science (Washington, D.C.), 299: 107-109. doi:10.1126/science. 1079365. PMID: 12511651.

Thorrold, S.R., Jones, C.M., Campana, S.E., McLaren, J.W., and Lam, J.W.H. 1998. Trace element signatures in otoliths record natal river of juvenile American shad (Alosa sapidissima). Limnol. Oceanogr. 43: 1826-1835.

Thorrold, S.R., Latkoczy, C., Swart, P.K., and Jones, C.M. 2001. Natal homing in a marine fish metapopulation. Science (Washington, D.C.), 291: 297-299. doi:10.1126/science.291.5502. 297. PMID:11209078.

Thorrold, S.R., Jones, G.P., Planes, S., and Hare, J.A. 2006. Transgenerational marking of embryonic otoliths in marine fishes using barium stable isotopes. Can. J. Fish. Aquat. Sci. 63: 1193-1197. doi:10.1139/F06-048.

Victor, B.C. 1986. Larval settlement and juvenile mortality in a recruitment-limited coral reef fish population. Ecol. Monogr. 56: 145-160. doi:10.2307/1942506.

Warner, R.R., Swearer, S.E., Caselle, J.E., Sheehy, M.S., and Paradis, G.L. 2005. Natal trace-elemental signatures in the otoliths of an open-coast fish. Limnol. Oceanogr. 50: 1529-1542.

White, J.W., and Ruttenberg, B.I. 2007. Discriminant function analysis in marine ecology: some common oversights and their solutions. Mar. Ecol. Prog. Ser. 329: 301-305. doi:10.3354/ meps329301.

Zacherl, D.C. 2005. Spatial and temporal variation in statolith and protoconch trace elements as natural tags to track larval dispersal. Mar. Ecol. Prog. Ser. 290: 145-163. doi:10.3354/ meps 290145 .

\section{Appendix A}

Table A1. Estimates of precision (\% RSD) and limits of detection (LOD).

\begin{tabular}{lllll}
\hline Element & $\begin{array}{l}\text { NIST \%RSD, } \\
\text { low resolution }\end{array}$ & $\begin{array}{l}\text { NIST \%RSD, } \\
\text { medium resolution }\end{array}$ & $\begin{array}{l}\text { LOD, } \\
\text { low resolution }\end{array}$ & $\begin{array}{l}\text { LOD, } \\
\text { medium resolution }\end{array}$ \\
\hline $\mathrm{Mg} / \mathrm{Ca}$ & 9 & 20 & 0.01 & 0.006 \\
$\mathrm{Mn} / \mathrm{Ca}$ & NA & 16 & NA & 2.32 \\
$\mathrm{Fe} / \mathrm{Ca}$ & NA & 23 & NA & 13.3 \\
$\mathrm{Zn} / \mathrm{Ca}$ & NA & 42 & NA & 15.5 \\
$\mathrm{Sr} / \mathrm{Ca}$ & 23 & 37 & 0.09 & 0.36 \\
$\mathrm{Ba} / \mathrm{Ca}$ & 9 & 24 & 0.12 & 2.33 \\
$\mathrm{~Pb} / \mathrm{Ca}$ & 12 & 23 & 0.24 & 3.85 \\
\hline
\end{tabular}

Note: Estimates of precision were obtained by analyzing NIST 612 glass standards using the same laser and instrument settings used for otoliths. LODs were obtained by using the same instrument settings used for otoliths, with no material ablated. Note that for limits of detection, values for $\mathrm{Mg} / \mathrm{Ca}$ and $\mathrm{Sr} / \mathrm{Ca}$ are given in $\mathrm{mmol} \cdot \mathrm{mol}^{-1}$, and those for $\mathrm{Mn} / \mathrm{Ca}, \mathrm{Fe} / \mathrm{Ca}, \mathrm{Zn} / \mathrm{Ca}, \mathrm{Ba} / \mathrm{Ca}$, and $\mathrm{Pb} / \mathrm{Ca}$ are given in $\mu \mathrm{mol} \cdot \mathrm{mol}^{-1}$. Values for $\% \operatorname{RSD}(\%$ relative standard deviation) are dimensionless. NA, not applicable. 
Table A2. Cutoff values for data filter and transformations used.

\begin{tabular}{lrll}
\hline Element & $\begin{array}{c}\text { Maximum } \\
\text { value }\end{array}$ & $\begin{array}{l}\text { Maximum } \\
\text { \%RSD }\end{array}$ & Transformation \\
\hline $\mathrm{Mg} / \mathrm{Ca}$ & 3 & 100 & Natural log \\
$\mathrm{Mn} / \mathrm{Ca}$ & 2300 & 200 & Double square root \\
$\mathrm{Fe} / \mathrm{Ca}$ & 250 & 200 & Square root \\
$\mathrm{Zn} / \mathrm{Ca}$ & 250 & 200 & Square root \\
$\mathrm{Sr} / \mathrm{Ca}$ & 5 & 50 & None \\
$\mathrm{Ba} / \mathrm{Ca}$ & 75 & 100 & Natural log \\
$\mathrm{Pb} / \mathrm{Ca}$ & 5 & 200 & Natural log \\
\hline
\end{tabular}

Note: Note that for maximum value, values of $\mathrm{Mg} / \mathrm{Ca}$ and $\mathrm{Sr} / \mathrm{Ca}$ are given in $\mathrm{mmol} \cdot \mathrm{mol}^{-1}$, and those for $\mathrm{Mn} / \mathrm{Ca}, \mathrm{Ba} / \mathrm{Ca}$, and $\mathrm{Pb} / \mathrm{Ca}$ are given in $\mu \mathrm{mol} \cdot \mathrm{mol}^{-1}$. Values for maximum \%RSD (\% relative standard deviation) are dimensionless.
Table A3. Weights for the discriminant functions, by element.

\begin{tabular}{|c|c|c|c|}
\hline Analysis (figure) & Element & DF1 & DF2 \\
\hline \multirow[t]{4}{*}{ By island (Fig. 3a) } & $\mathrm{Sr}$ & -0.14 & -0.64 \\
\hline & $\mathrm{Ba}$ & -1.05 & 0.45 \\
\hline & $\mathrm{Pb}$ & 0.85 & 0.38 \\
\hline & $\mathrm{Mn}$ & 0.98 & 0.09 \\
\hline \multirow[t]{4}{*}{ Hawaii, all sites (Fig. 3b) } & $\mathrm{Sr}$ & 0.57 & 0.05 \\
\hline & $\mathrm{Ba}$ & 0.95 & -0.17 \\
\hline & $\mathrm{Pb}$ & -0.12 & 1.14 \\
\hline & $\mathrm{Mn}$ & 0.31 & 0.37 \\
\hline \multirow[t]{4}{*}{ Hawaii, focal sites (Fig. 3c) } & $\mathrm{Sr}$ & 0.76 & -0.50 \\
\hline & $\mathrm{Ba}$ & 1.40 & 0.06 \\
\hline & $\mathrm{Pb}$ & -0.21 & 0.88 \\
\hline & $\mathrm{Mn}$ & -0.32 & -0.03 \\
\hline \multirow[t]{4}{*}{ Maui (Fig. 3d) } & $\mathrm{Sr}$ & 0.63 & 0.39 \\
\hline & $\mathrm{Ba}$ & 0.75 & -0.79 \\
\hline & $\mathrm{Pb}$ & 1.50 & 1.06 \\
\hline & $\mathrm{Mn}$ & 0.98 & 1.16 \\
\hline \multirow[t]{4}{*}{ Oahu (Fig. 3e) } & $\mathrm{Sr}$ & 0.14 & 0.48 \\
\hline & $\mathrm{Ba}$ & -1.76 & 0.04 \\
\hline & $\mathrm{Pb}$ & -0.08 & 0.89 \\
\hline & $\mathrm{Mn}$ & 1.71 & 0.66 \\
\hline \multirow[t]{4}{*}{ Kauai (Fig. 3f) } & $\mathrm{Sr}$ & 0.85 & 0.14 \\
\hline & $\mathrm{Ba}$ & -0.05 & 1.12 \\
\hline & $\mathrm{Pb}$ & 0.37 & -0.28 \\
\hline & $\mathrm{Mn}$ & -0.21 & -0.67 \\
\hline \multirow[t]{3}{*}{ Recruits, by island (Fig. $6 a$ ) } & $\mathrm{Sr}$ & -0.06 & 0.95 \\
\hline & $\mathrm{Ba}$ & 1.08 & 0.21 \\
\hline & $\mathrm{Mn}$ & -0.56 & -0.33 \\
\hline \multirow[t]{3}{*}{ Recruits, Hawaii (Fig. 6b) } & $\mathrm{Sr}$ & 0.76 & 1.07 \\
\hline & $\mathrm{Ba}$ & 1.33 & -0.45 \\
\hline & $\mathrm{Mn}$ & -0.19 & 1.00 \\
\hline \multirow[t]{3}{*}{ Recruits, Oahu (Fig. 6c) } & $\mathrm{Sr}$ & 0.17 & 0.79 \\
\hline & $\mathrm{Ba}$ & -1.64 & 0.65 \\
\hline & $\mathrm{Mn}$ & 1.62 & 0.59 \\
\hline
\end{tabular}

Note: Each set of values corresponds to a specific analysis for a specific figure. DF, discriminant function. 